\title{
Sistem Pemesanan Jasa Perbaikan Komputer Dengan Location Based Services (LBS) Berbasis Android
}

\author{
Obie Jagad Prakoso ${ }^{1}$, Adi Muhajirin ${ }^{1}$, Dwi Budi Srisulistiowati 1, * \\ * Korespondensi: e-mail: dwibudi@dsn.ubharajaya.ac.id
}

\begin{abstract}
1 Program Studi Teknik Informatika, Fakultas Teknik, Universitas Bhayangkara Jakarta Raya; Jl. Raya Perjuangan, Marga Mulya, Bekasi Utara, Jawa Barat 17121. Telp: 021 88955882, 889955883, e-mail: obieprakoso@gmail.com, adimuhajirin@dsn.ubharajaya.ac.id dwibudi@ubharajaya.ac.id
\end{abstract}

Submitted: 16 Maret 2020 Revised: 6 April 2020 Accepted: 27 April 2020 Published: 20 Mei 2020

\begin{abstract}
Computers can be said to be the primary goods and become a necessity for all circles, both for individuals and organizations. In this case in need of computer maintenance to support the performance of these computer devices in order to run with good conditions in high intensity. On the other hand the maintenance will take time in because need to seek care services that are in various areas. Computer repair service providers are still in the shopping area or in certain locations so if you want to fix the problems that can be on the computer must go to the stores that provide computer repair services, it will take more time to find repair services, Therefore, An application is needed to help the search engine technician quickly. Target to be achieved is to provide an application System Booking Computer Repair Services on the mobile. This application consists of 3 users, namely admin to process data entry, user as user who will get computer repair service, and technicians as people who will come to the location of the user to repair the computer.
\end{abstract}

Keywords: Booking, Location Based Services, mobile apps.

\section{Abstrak}

Komputer dapat dikatakan menjadi barang primer dan menjadi kebutuhanbagi semua kalangan, baik bagi individu maupun organisasi. Dalam hal ini diperlukan perawatan komputer untuk menunjang kinerja dari perangkat computer tersebut agar dapat berjalan dengan kondisi baik dalam intensitas yang tinggi. Disisi lain perawatan akan memakan waktu di karenakan perlu mencari jasa perawatan yang berada di berbagai wilayah. Penyedia jasa perbaikan computer masih banyak berada di tempat perbelanjaan atau di lokasi-lokasi tertentu maka bila ingin memperbaiki masalah yang di dapat pada komputer harus mendatangi toko-toko yang menyediakan jasa perbaikan komputer, maka akan memakan waktu lebih untuk mencari jasa perbaikan, Oleh sebab itu, dibutuhkan suatu aplikasi untuk membantu pencarian teknisi komputer dengan cepat.Target yang ingin dicapai adalah menyediakan sebuah aplikasi Sistem Pemesanan Jasa Perbaikan Komputer secara mobile. Aplikasi ini terdiri dari 3 pengguna, yaitu admin untuk mengolah data masuk, user sebagai penguna yang akan mendapatkan layanan perbaikan komputer, dan teknisi sebagai orang yang akan datang ke lokasi user untuk memperbaiki komputer.

Kata Kunci: pemesanan, Location Based Services, aplikasi mobile.

\section{Pendahuluan}

Berdasarkan hasil pengamatan yang telah dilakukan di masyarakat pada saat ini ada beberapa orang yang memiliki kemampuan di bidang perbaikan komputer namun tidak memiliki toko sendiri melainkan hanya menjadi karyawan toko perbaikan komputer, hal itu dikarenakan banyak masyarakat yang ingin memperbaiki komputer selalu mencari toko yang menyediakan jasa perbaikan komputer di karenakan belum adanya fasilitas yang menampung penyedia jasa perbaikan komputer 
baik itu perorangan yang tidak memiliki toko maupun yang telah memiliki toko sendiri agar masyarakat tidak perlu repot mencari toko yang menyediakan jasa perbaikan komputer.

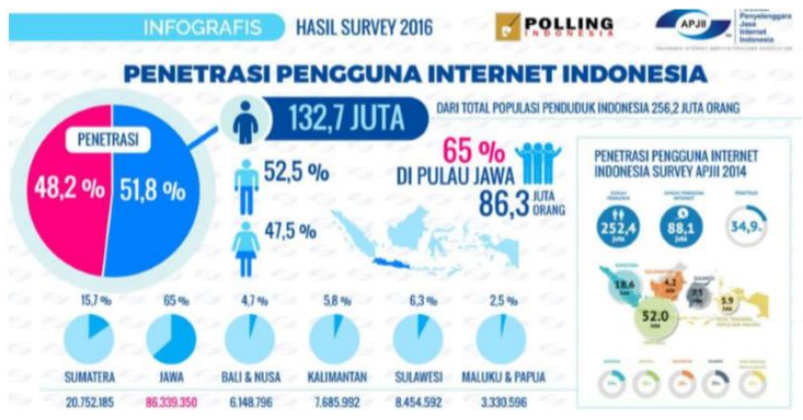

Sumber : https://www.apjii.or.id/, (Diakses Pada 9 Mei 2017)

Gambar 1. Pengguna Jasa Internet Di Indonesia 2016

Berdasarkan Gambar 1 pengguna jasa internet di indonesia mencapai 132,7 juta pengguna, penggunaan jasa internet paling banyak adalah di wilayah jawa yang mencapai $65 \%$ atau 86.339 .350 pengguna. Maka dari itu di indonesia penggunaan internet sudah menjadi kebutuhan utama untuk beraktifitas dan mengembangkan berbagai informasi.

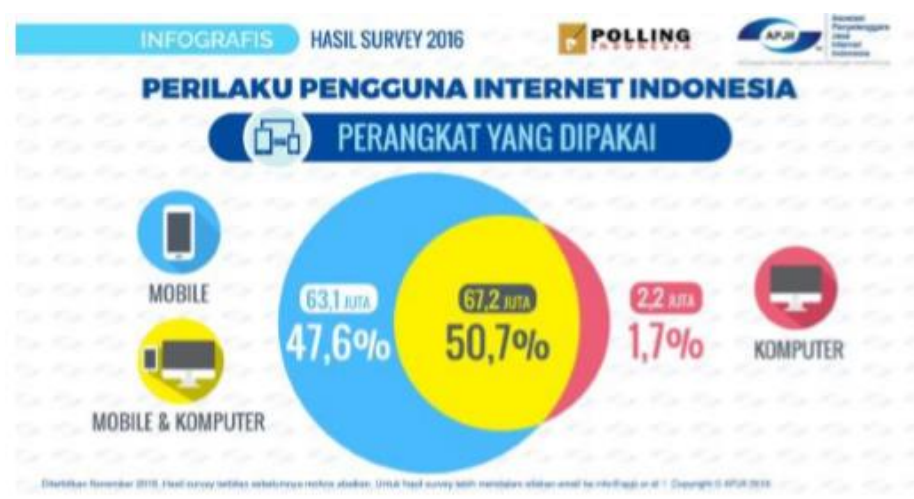

Sumber : https://www.apjii.or.id/ (Diakses Pada 9 Mei 2017)

Gambar 2. Perangkat yang dipakai untuh internet 2016

Dari gambar 2Penggunaan perangkat untuk mengakses internet di dominasi oleh perangkat mobile $46,6 \%$ di urutan kedua adalah komputer $1,7 \%$. Hal ini dikarenakan perangkat mobile memiliki bentuk yang memudahkan di bawa kemana saja untuk mengakses internet.

Maka dalam penelitian ini akan dibuat sistem pemesanan jasa teknisi secara online agar memudahkan pengguna jasa dalam hal ini perbaikan komputer untuk mendapatkan teknisi lebih cepat.

Batasan masalah penelitian ini sebagai berikut: 1. Membuat sistem yang mampu menghubungkan teknisi perbaikan kompter dengan masyarakat secara online. 2. Membuat sistem yang dapat menampung penyedia jasa perbaikan komputer baik itu yang memiliki toko sendiri ataupun per seorangan.

Tujuan dari penelitian ini adalah: 1). Memudahkan masyarakat dalam mencari penyedia jasa perbaikan komputer. 2). Menyediakan tempat bagi seseorang yang mempunyai kemampuan dalam memperbaiki komputer tetapi tidak memiliki toko. 
Manfaat dari penelitian ini adalah: a). Masyarakat tidak perlu mendatangi tempat penyedia jasa perbaikan untuk memperbaiki komputer. b). Seorang yang mempunyai kemampuan dalam memperbaiki komputer tidak perlu mempunyai toko sendiri untuk membuka jasa perbaikan.

\section{Metode Penelitian}

Metode yang digunakan dalam melakukan pengumpulan data adalah observasi, wawancara, kuisioner dan studi Pustaka yaitu: a) Observasi yang dilakukan penulis adalah untuk mengamati dan mengetahui secara langsung jalannya sistem yang sedang berjalan saat itu dan proses kerja dari tugas masing-masing serta melihat format-format laporan dalam perusahaan tersebut yang di gunakan saat itu, b) Kuesioner digunakan untuk mencari bukti informasi apa yang disampaikan di pencarian lokasi gedung dan ruangan secara detail, dan menyeluruh. c) Studi Pustaka, Pada metode kepustakaan dilakukan pencarian dan pengumpulan data berdasarkan sumber internet, buku-buku referensi, ataupun sumber-sumber lain yang diperlukan untuk merancang dan mengimplementasikan aplikasi yang akan di buat.

Metode Pengembangan Sistem Metode pengembangan sistem yang digunakan dalam penyusunan tugas akhir (skripsi) ini adalah Rapid Application Development (RAD), yang dilakukan dengan tahapan sebagai berikut: 1). Pemodelan bisnis Tahapan untuk mengumpulakan kebutuhan informasi yang terkait dalam penelitian ini. 2). Pemodelan data Tahapan mengumpulan data yang terkait dengan informasi yang sudah dikumpulkan dan menjadikan data yang dikumpulkan menjadi informasi. 3). Pemodelan proses Menerapkan informasi dan data yang sudah didapatkan untuk diproses menjadi satu informasi yang siap untuk diimplemetasikan. 4). Pembuatan aplikasi Tahapan ini adalah tahap selanjutnya untuk membuat sebuah sistem yang diusulkan berdasarkan informasi yang sudah diproses dari pengumpulan informasi dan data. 5). Pengujian dan pergantian Tahapan ini adalah tahapan untuk melakukan pengujian pada sistem yang diusulkan, jika semua sudah teruji maka tahapan pengembangan sistem selesai.

Rapid Aplication Development (RAD) adalah model proses pengembangan perangkat lunak yang bersifat inkremental terutama untuk waktu pengerjaan yang pendek. Model RAD adalah adaptasi dari model air terjun versi kecepatan tinggi dengan menggunakan model air terjun untuk pengembangan setiap komponen perangkat lunak. Jika kebutuhan perangkat lunak dipahami dengan baik dan lingkup perangkat lunak dibatasi dengan baik sehingga tim dapat menyelesaikan pembuatan perangkat lunak dengan waktu yang pendek. Model RAD membagi tim pengembang menjadi beberapa tim untuk mengerjakan beberapa komponen masing-masing tim pengerjaan dapat dilakukan secara pararel. Berikut gambar dari model RAD (Sukamto \& Shalahuddin, 2013). 


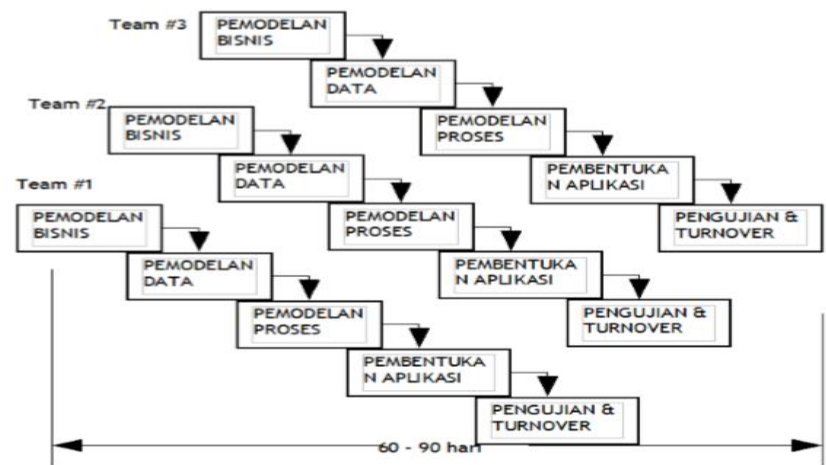

Sumber: (Sukamto \& Shalahuddin, 2013).

Gambar 3. Ilustrasi Model RAD

\section{Hasil dan Pembahasan}

Proses perancangan pada aplikasi ini menggunakan metode RAD (Rapid Application Development) dimana terdapat beberapa tahap dalam pengerjaannya. Dimulai dari proses menganalisa tujuan peranvangan aplikasi, perancangan sampai dengan pelaksanannya. Untuk membantu masyarakat dalam mendapatkan jasa perbaikan computer dengan cepat, maka penulis berencana membuat aplikasi berbasis android menggunakan Android studio dengan bahasa pemrograman Java. Berikut tahapan-tahapan dalam perancangan aplikasi dengan menggunakan metode RAD (Rapid Application Development):

Usecase Diagram Untuk menindaklanjuti hasil analisis tujuan pengembangan sistem dan analisis kebutuhan sistem diperlukan penjelasan mengenai gambaran sistem dan aktor yang terlibat secara keseluruhan dalam bentuk Usecase diagram. Usecase diagram memberi gambaran singkat hubungan antara Usecase, aktor dan sistem. Aktor adalah pemain atau pengguna sedangkan Usecase adalah apa yang dimainkan atau digunakan dengan relation sebagai penunjuknya. Di dalam Usecase ini akan diketahui fungsi-fungsi apa saja yang berada pada sistem yang dibuat.

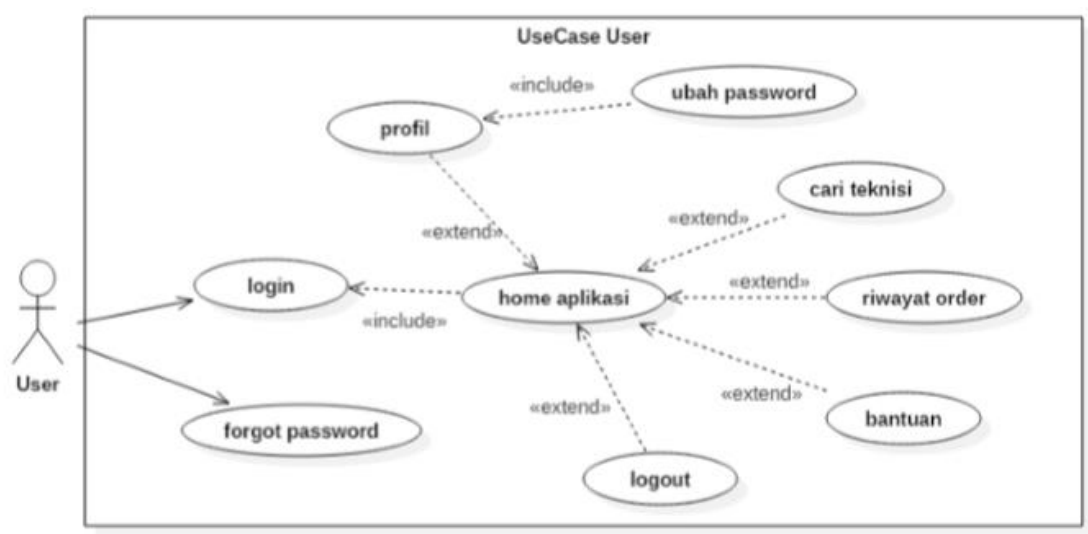

Sumber: Hasil Penelitian (2019)

Gambar 4. Usecase Diagram User

Pada gambar 4 menjelaskan mengenai bagian-bagian yang tersedia pada layanan yang di berikan kepada user setelah berhasil login oleh aplikasi pemesana jasa perbaikan komputer. 


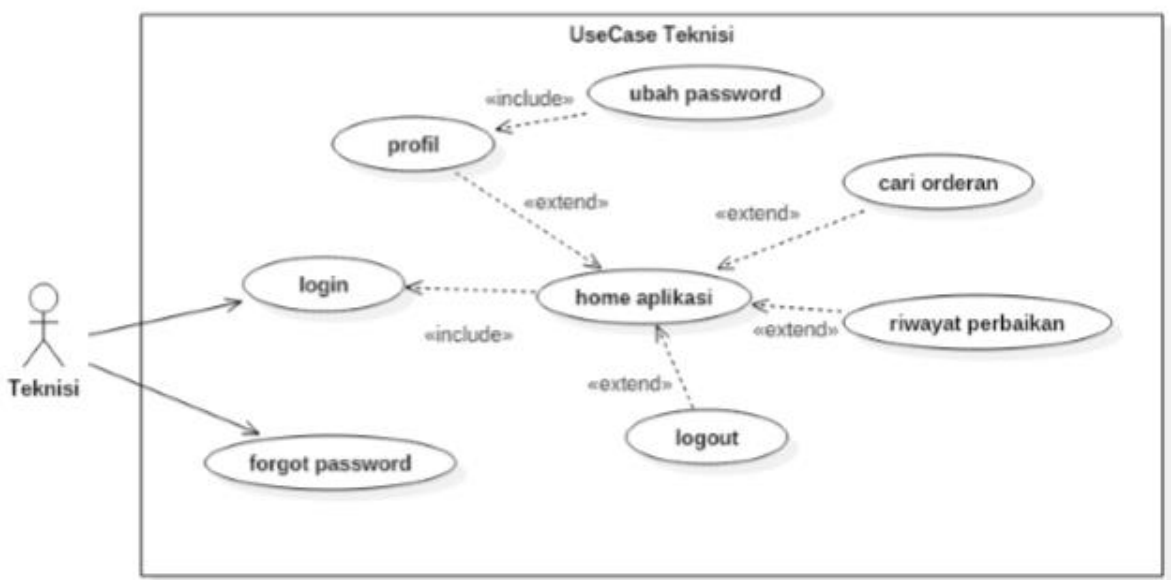

Sumber: Hasil Penelitian (2019)

Gambar 5. Usecase Diagram Teknisi

Pada Gambar 5 menjelaskan mengenai bagian-bagian yang tersedia pada layanan yang di berikan kepada para teknisi setelah berhasil login oleh aplikasi pemesana jasa perbaikan komputer.

Activity Diagram Activity Diagram di desain untuk memperlihatkan apa yang terjadi selama suatu proses atau operasi berlangsung. Pemprosesan pada suatu aktifitas yang telah selesai akan dikirimkan ke aktifitas berikutnya secara otomatis untuk melakukan aktifitas berikutnya. Garis berarah menunjukan perpindahan aktifitas dari suatu aktifitas berikutnya. Berikut adalah activity diagram dalam perancangan aplikasi Perancangan Sistem Pemesanan Jasa Perbaikan Komputer berbasis Android:

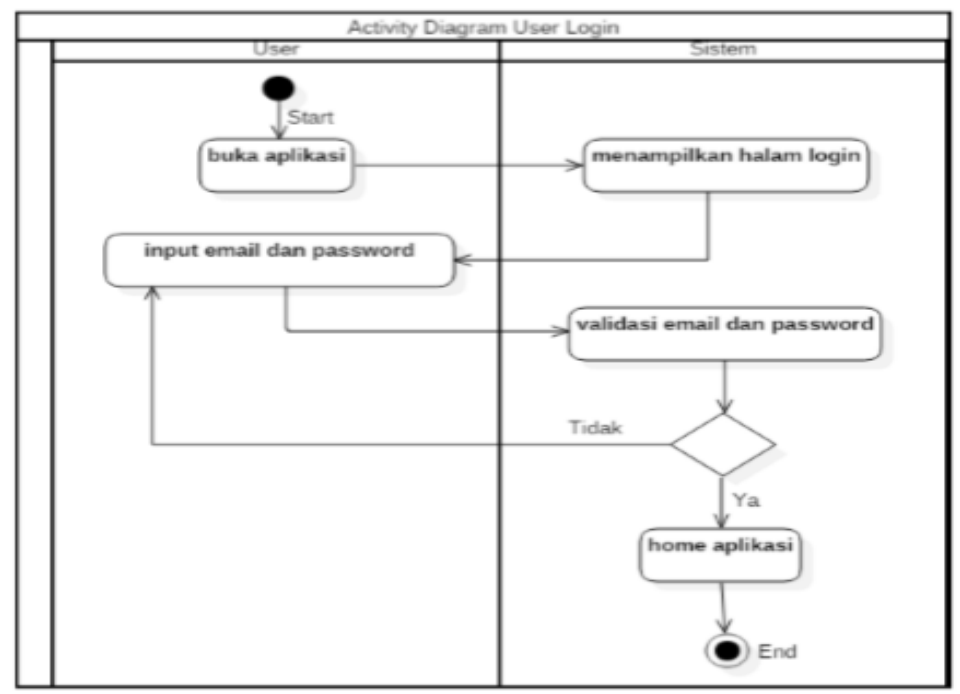

Sumber: Hasil Penelitian (2019)

Gambar 6. Activity Diagram user login

Gambar 6 menjelaskan Activity login pada user di aplikasi pencarian jasa perbaikan komputer. user dapat memulai dengan melakukan login terlebih dahulu, jika login gagal maka sistem akan kembali ke menu login, jika berhasil maka user akan masuk pada menu utama dan dapat melakukan order. 
Sequence diagram menggambarkan kolaborasi dinamis antara sejumlah objek. Sequence menjelaskan interaksi antar objek yang disusun dalam suatu urutan waktu yaitu urutan kejadian yang dilakukan oleh seorang actor dalam menjalankan sistem. Diagram ini menunjukkan bagaimana detail operasi yang dilakukan, pesan apa yang dikirim dan kapan terjadinya.

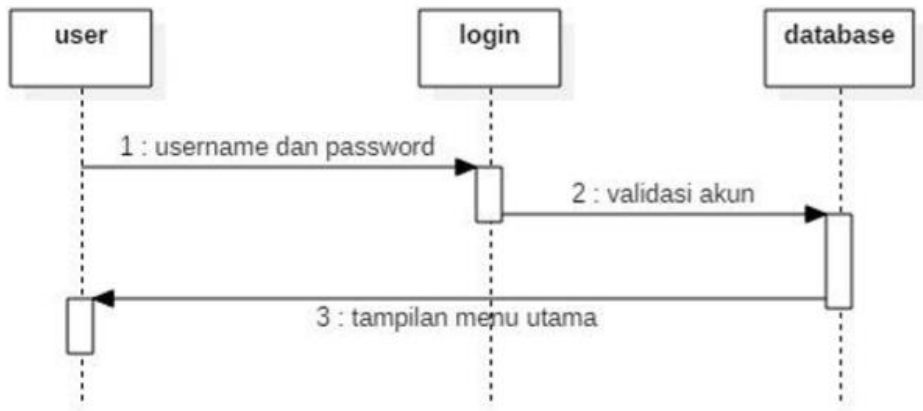

Sumber: Hasil Penelitian (2019)

Gambar 7. Squence Diagram user login

Pada Gambar 7 menjelaskan mengenai proses yang terjadi ketika user ingin melakukan login terlebih dahulu, jika gagal sistem akan kembali ke index, jika berhasil maka akan masuk halaman utama kemudian pilih menu yang diinginkan.

Class Diagram Class Diagram adalah sebuah spesifikasi yang jika diinstansiasi akan menghasilkan sebuah objek dan merupakan inti dari pengembangan dan desain berorientasi objek. Class menggambarkan keadaan (atribut/properti) suatu sistem, sekaligus menawarkan layanan untuk memanipulasi keadaan tersebut (metoda/fungsi).

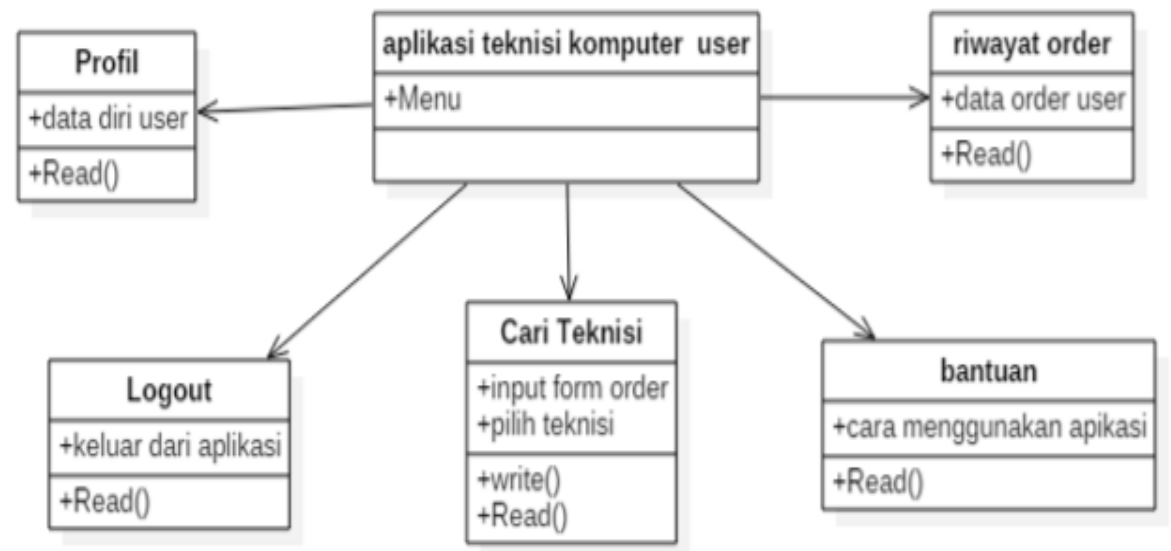

Sumber: Hasil Penelitian (2019)

$$
\text { Gambar 8. Class Diagram User }
$$

State Machine Diagram menelusuri individu-individu objek melalui keseluruhan daur ulang hidupnya, menspesifikasikan semua urutan yang mungkin dari pesan-pesan yang diterima oleh objek, bersama dengan tanggapan atas pesan tersebut. 


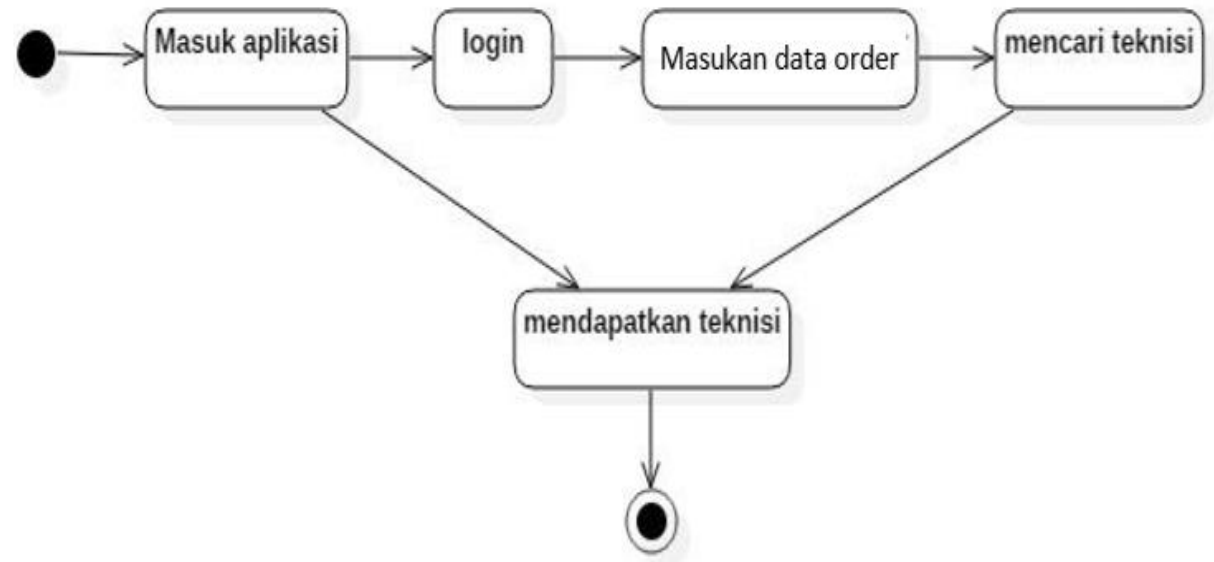

Sumber: Hasil Penelitian (2019)

Gambar 8. State Machine Diagram Sistem Pemesanan Jasa Perbaikan Komputer (User)

Deployment Diagram Diagram ini menggambarkan akan penempatan dari komponen dan bagaimana komponen tersebut ditempatkan dalam infrastruktur sistem. Berikut adalah deployment diagram perancangan aplikasi pencarian jasa perbaikan komputer berbasis Android:

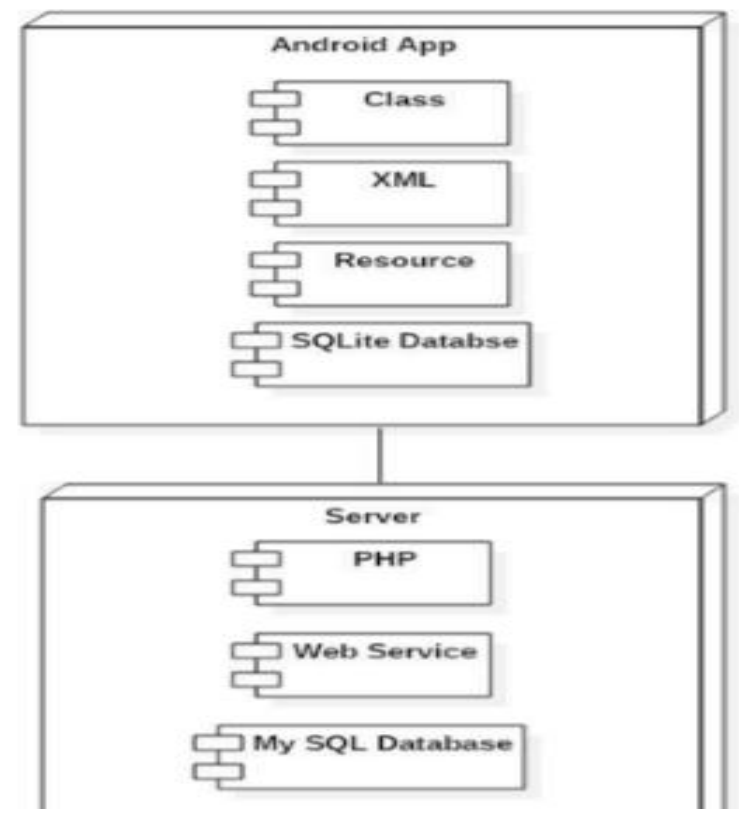

Sumber: Hasil Penelitian (2019)

Gambar 9. Deployment Diagram Sistem Pemesanan Jasa Perbaikan Komputer Dengan Location Based Services (LBS) Berbasis Android

Pada gambar 9 menjelaskan mengenai Deployment Diagram, jadi didalam infrastruktur android app ada beberapa komponen yaitu class, xml, resource, SQLite sebagai database di aplikasi. Dan ada juga infrastruktur server didalam nya terdapat beberapa komponen antara lain PHP, web service, dan My SQL.

Daftar akun merupakan rancangan tampilan jika user, teknisi, dan admin ingin menggunakan aplikasi ini namun belum memilik akun. Berikut tampilan daftar akun pada aplikasi ini 


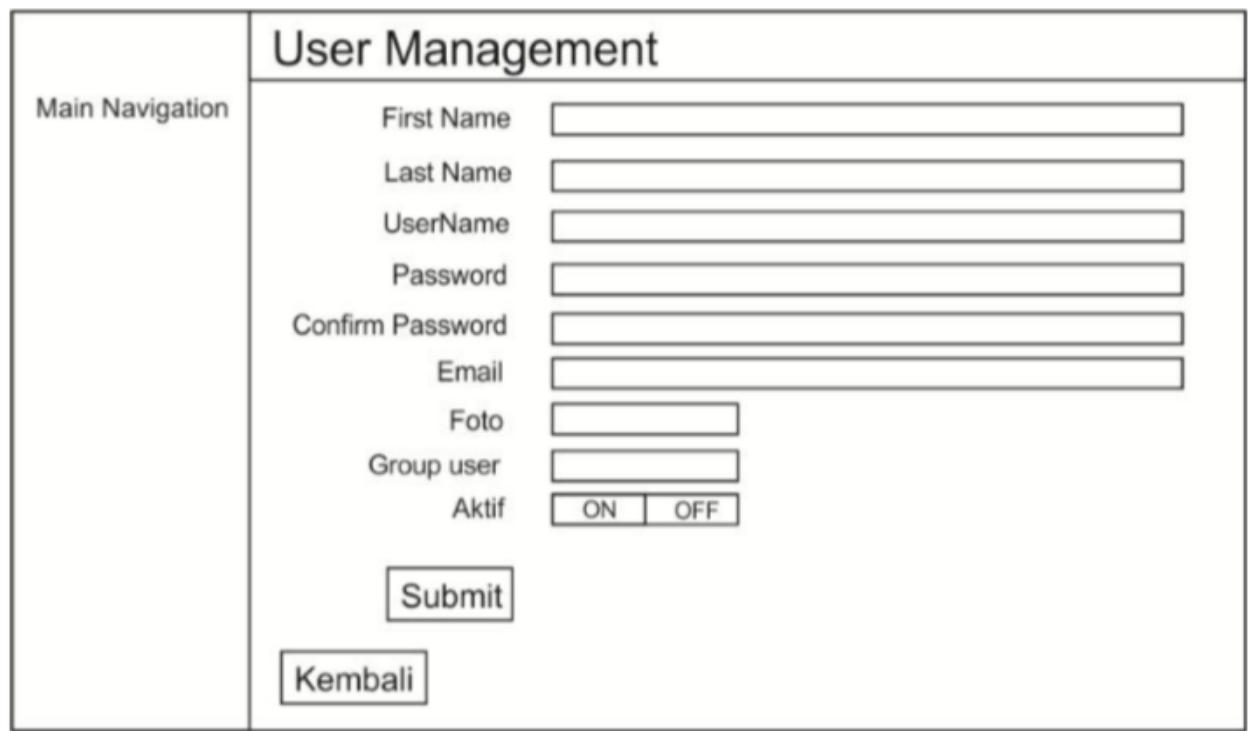

Sumber: Hasil Penelitian (2019)

Gambar 9. Perancangan Antarmuka Daftar Akun Admin

Implementasi antarmuka akan menampilkan implementasi tampilan dari program aplikasi yang dibangun sesuai perancangannya. Implementasi antarmuka "Perancangan Sistem Pemesanan Jasa Perbaikan Komputer" yaitu:

Tampilan Icon Aplikasi Teknisi Komputer dapat dilihat pada Gambar 10, diantaranya selain icon Teknisi terdapat icon yang lainnya.

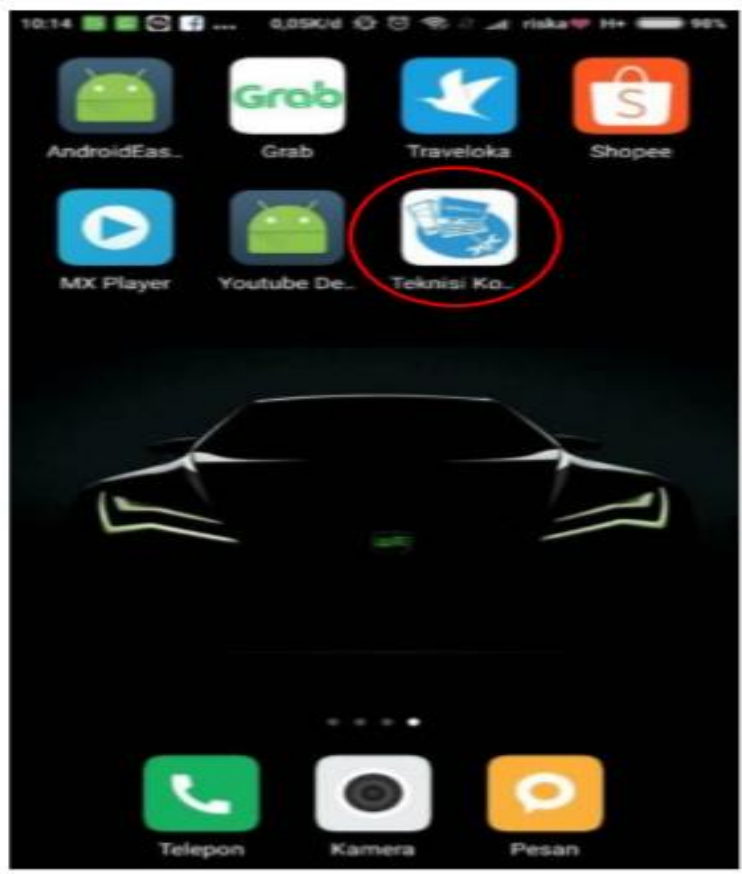

Sumber: Hasil Penelitian (2019)

Gambar 10. Tampilan Icon Aplikasi Teknisi Online

Tampilan Home Admin dapat dlihat pada Gambar 11 yang diantaranya menampilkan menu manage pelanggan. 


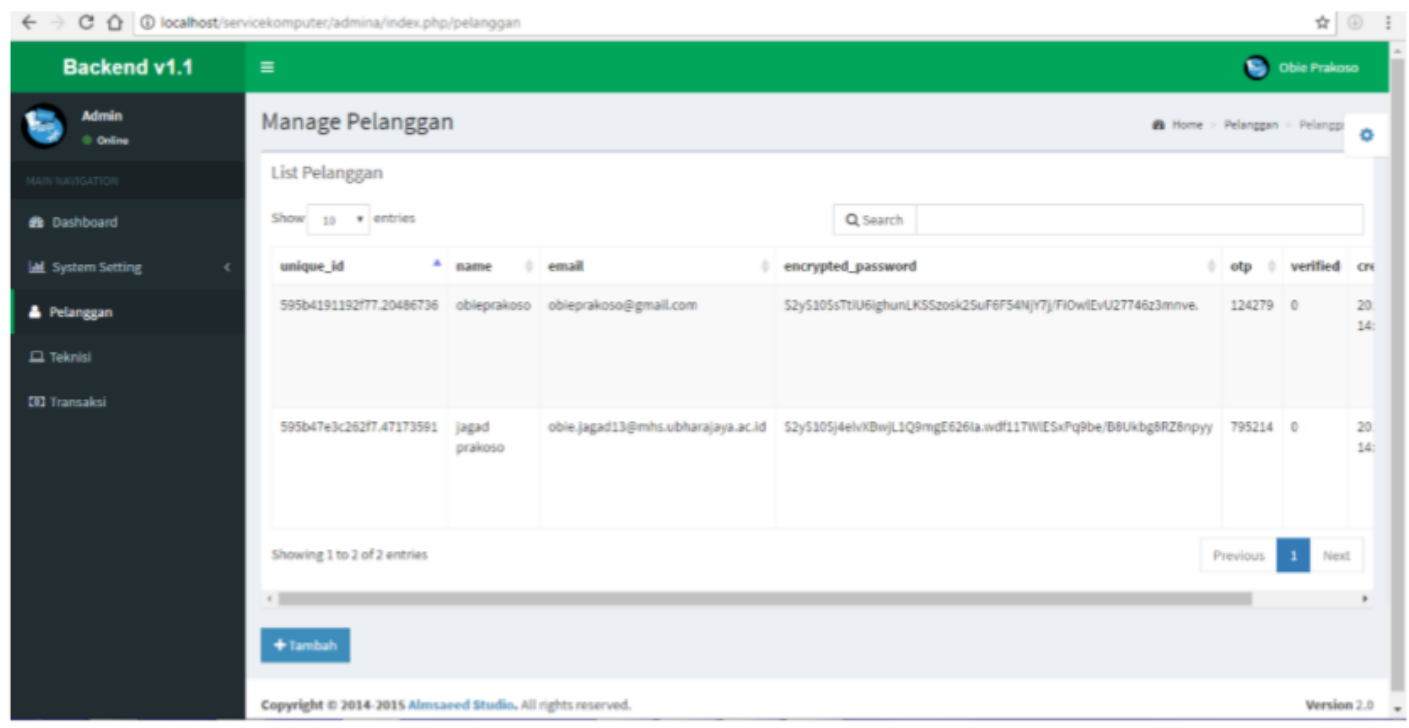

Sumber: Hasil Penelitian (2019)

Gambar 11. Tampilan Home Admin

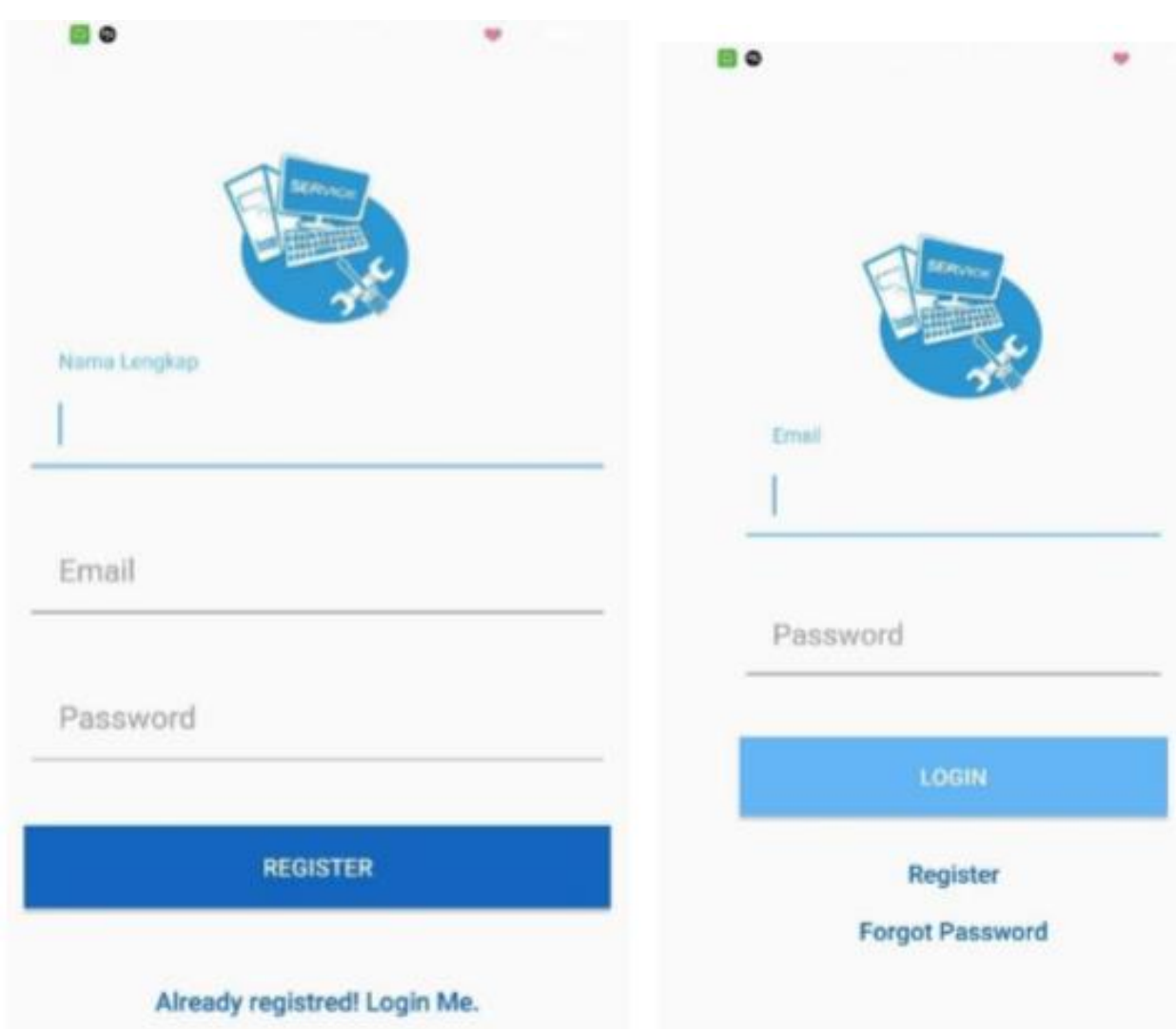

Sumber: Hasil Penelitian (2019)

Gambar 12. Tampilan Login User dan Tampilan Register 
Pada Gambar 12 dapat dijelaskan tentang tampilan login user dan tampilan register user.

\section{Kesimpulan}

Berdasarkan pembahasan sebelumnya, maka penulis mencoba memberikan kesimpulan terhadap masalah pada aplikasi Perancangan Sistem Pemesanan Jasa Perbaikan Komputer sebagai berikut: 1. Perancangan aplikasi Perancangan Sistem Pemesanan Jasa Perbaikan Komputer dapat membantu masyarakat yang ingin memperbaiki komputer tanpa harus datang ke toko. 2. Sistem ini membantu pekerja jasa perbaikan komputer secara online tanpa harus memiliki toko fisik 3 . Mempersingkat untuk masyarakat menemukan tempat jasa perbaikan komputer di wilayah nya. 4. Sistem ini mefasilitasi seseorang yang memiliki keahlian kusus dalam memperbaiki komputer. Penulis menyarankan beberapa hal yang terkait "Perancangan Sistem Pemesanan Jasa Perbaikan Komputer" sebagai berikut: 1. Diharapkan Pengembangan Selanjutnya Aplikasi bisa di jalankan sistem operasi lain untuk menambah lingkungan pengguna. 2. Diharapkan Aplikasi yang akan di kembangkan dapat membuat sistem transaksi secara online. 3. Aplikasi yang akan dikembangkan ditambah ruang lingkup bukan hanya untuk komputer tetapi bisa juga peralatan elektronik lainnya.

\section{Daftar Pustaka}

Sutabri, T. (2012). Analisis Sistem Informasi. Yogyakarta: Andi.

Maulana, I. (2014). Pengukuran GPS Geodetik dan Terresial Leser (TSL) untuk Pembangunan Rel Kereta Api Baru di Menteng Jaya Jakarta.

Sutabri, T. (2014). Pengantar Teknologi Informasi: Andi.

Kennet, K, E. 2010. Analisis dan perancangan sistem. Jakarta: Indeks.

Sutabri, T. (2013). Komputer dan masyarakat. Yogyakarta: Andi

Kasman, A. D. (2015). Trik Kolaborasi Android Dengan PHP \& MySQL. Yogyakarta: Lokomedia

Nazaruddin, S. H. (2012). Pemrogramman Aplikasi Mobile Smartphone dan Tablet PC Berbasis Android.Bandung: Informatika

Hidayat, B, R., \& Februariyanti, H. (2013). Aplikasi Location Based Service (LBS) Perancangan Lokasi Taxi Pada Android di Kota Semarang. Dinamika Informatika, 18.

Mahdia, F., \& Noviyanto, F. (2013). Pemanfaatan Google Maps API Untuk Pembangunan Sistem Informasi Manajemen Bantuan Logistik Pasca Bencana Alam Berbasis Mobile Web. Jurnal Sarjana Teknik Informatika, 164

Satyaputra, A., \& Maulina, E, A. (2016). Let's Build Your Android Apps With Android Studio. Jakarta: Elex Media Komputindo

Fathansyah. (2015). Basis Data. Bandung: Informatika.

Sukamto, R.A. \& Shalahudin, M. (2015). Rekayasa Perangkat Lnak Terstruktur dan Berorientasi Objek. Bandung: Informatika

Kotler, P. Armstrong, G. (2012). Principle of Marketing, Fourteenth Edition. Pearson Education Limited, England.

Ariani, D, W. (2009). Manajemen Operasi Jasa. Yogyakarta: Graha Ilmu. 